Synthese

doi.org/10.1007/s11229-018-01898-9

\title{
Tolerance, Flexibility and the Application of Kind Terms
}

Genoveva Martí (ICREA and University of Barcelona)

Lorena Ramirez-Ludeña (Pompeu Fabra University)

Keywords: kind terms, legal disagreements

\begin{abstract}
We explore two ways of distinguishing the semantic operation of kind terms. First, we focus on a distinction between terms with a flexible vs. terms with an inflexible semantics. Flexibility depends on whether some changes in the domain of application are taken to be possible while being consistent with past usage and what is intuitively the same meaning. On the other hand we discuss terms whose mode of operation is tolerant, in that the cohabitation in the speakers' community of more than one use or practice of use of the term in question is accepted. Those terms contrast with terms that operate in a strict way restricting severely the legitimacy of different uses that cut the domain of application in different ways. Among the latter we include terms with an ethical component and terms whose correct application involves high stakes. These distinctions are not new, since the phenomena that we identify as flexibility and tolerance have been observed, although in our view they have not been properly systematized and assessed. We argue that the two distinctions throw light on the bases of some disputes and on some legal disagreements.
\end{abstract}

\section{Introduction}

In this paper we explore two pairs of distinctions in the semantic operation of kind terms. The phenomena we discuss have been observed before; but they have not been sufficiently explored, systematized and used to explain the basis of some judgments as regards the correctness of application of terms. In section 1 we discuss the distinction between terms with a flexible vs. terms with an inflexible semantics. Flexibility depends on whether some changes in the domain of application are taken to be possible while being consistent with past usage and preserving or refining the meaning of the term. In section 2 we discuss terms whose mode of operation is tolerant, in that the intentions of speakers and other factors that bestow meaning permit the cohabitation in the speakers' community of more than one use or practice of use of the term in question, in such a way that the different uses cut up roughly the same domain of application in different ways. Those terms contrast with terms that operate in a strict way restricting severely the legitimacy of different uses.

Section 1. Flexibility 
A fundamental tenet of semantic theory is the claim that the meaning, or intension, of a term determines its reference, or extension, or domain of application. This is an extremely plausible principle since it seems hardly debatable that what a term means determines what it should or should not be applied to. But this principle was for a long time interpreted in a rather strong way, understood to mean that whenever a term is introduced in the vocabulary of a language and bestowed a meaning, its reference or extension is determined once and for all, namely that it is determined for any object or any sample past, present or future, whether it is or it is not a member of the extension of the term. ${ }^{1}$

Hilary Putnam, for instance, appears to subscribe to such a strong interpretation of the principle in his seminal 1975 paper 'The Meaning of 'Meaning', at least when it comes to 'water', 'aluminum' and other kind terms he discusses: suppose that at time $m$ the term 'water' is introduced in the language. According to Putnam the meaning of that term establishes at that very time whether a sample $l$ of liquid that speakers will encounter later at time $m$ ' is or is not water. Applying the term to a sample $l$ that is not part of the pre-determined extension is an error and was an error, Putnam contends, before anyone knew the microstructure of water. ${ }^{2}$

The adherence to the strong once and for all interpretation of the principle that meaning determines extension, for all terms (and not just for the natural kind terms considered by Putnam), was for a long time the default position among semanticists. Mark Wilson certainly supposed the interpretation to be pervasive when he contested it in his 1982 paper 'Predicate Meets Property' a paper that is "partially intended as a commentary upon Hilary Putnam's 'The Meaning of 'Meaning'” (Wilson 1982: 549).

Jackman (1999) proposes a thought experiment, based on a story discussed by Wilson (1982): suppose that $s$ is a member of an isolated community ("the Druids"), that inhabit an island in which the class of birds and the class of flying things are coextensive. In that community they use the term 'ave' to refer to things in these coextensive classes, and they all have beliefs such as 'only aves can fly' and 'aves are living beings', which are true of the aves on the island. When $s$ first sees planes in the sky, he classifies them, unproblematically, as aves, and when he later sees one landing he forms the belief that not all aves are living beings. And, so the practice to apply 'ave' to planes catches on in the Druid community. Despite the initial lack of clarity derived from the fact that Druids had different beliefs associated to the term, they all consider that with 'ave' they have always referred to things that fly, and recognize that some of the previous beliefs they had about aves (e.g. they were all living beings) were false.

But suppose that $s$ had initially seen planes on the ground not realizing that they could fly. He might have classified them, also unproblematically, as non-aves. And had he afterwards seen them taking off, he would have concluded that not all things that fly are aves. Supposing this practice to catch on among Druids, $s$ and other Druids, would also have thought that with 'ave' they had always referred to birds, recognizing that some of

\footnotetext{
${ }^{1}$ The principle is supposed to apply to singular and general terms. For the purposes of the discussion here we leave aside singular terms.

${ }^{2}$ Of course, a change in meaning is always possible. For instance, the error may generalize and the community may end up applying 'water' to $l$ and similar samples.
} 
the previous beliefs they had about aves (such as that only aves could fly) were false. In none of the cases, the members of the community see themselves as having changed what they meant by 'ave'. Druids would understand that their current use is naturally derived from their previous use.

The example encourages us to think that it is not written in stone whether airplanes should or should not be under the extension of 'ave', simply because rather accidental facts about the way in which airplanes are first encountered have quite a decisive influence on the adjustment the Druids perform on their beliefs. In one case, the Druids abandon the belief that all aves are living beings, holding on to the belief that aves are flying things, thus reaching a consistent set of beliefs and attributions (an equilibrium, using Jackman's (1999) terminology) in which 'ave' applies to all flying things, living or not. Had $s$ first seen planes on the ground the equilibrium reached would include the belief that all aves are living beings, but exclude the belief that only aves fly. This is a puzzle case for the, at the time, pervasive strong interpretation of the principle that meaning determines extension. According to Wilson (who in his discussion uses 'bird' instead of Jackman's 'ave'):

The traditional response to our problem is to seek the "concept," "sense," or "universal" the prebomber Druids had associated with "bird" and study the extension determined by this intervening entity. A consequence of this account is that the Druids in one or both of our alternative stories must have "changed the meaning" of "bird." (Wilson 1982: 551)

But no obvious explanation for what such a change in meaning consisted in squares easily with the traditional strong interpretation for this is a case in which both the application, and the withdrawal, of the term 'ave' to planes appears to be consistent with the meaning of the term as it had been used by the Druid community.

The strong interpretation of the principle that meaning determines extension was the default position for a long time. It is nevertheless striking that both descriptivists and anti-descriptivist felt so committed to it. Take descriptivism. From the descriptivist point of view a term has a meaning in virtue of its being associated with a definite description. It seems unduly optimistic to expect the description to be sufficiently clear and so exhaustive as to delimit all the relevant properties that samples or exemplars that come up for classification have to possess. For instance suppose that the description associated with a term $M$ is 'the entities/samples that have properties $F, G$ and $H$ ', when an exemplar or a sample that has properties $\mathrm{F}, \mathrm{G}$ and $\mathrm{H}$, but also property $\mathrm{P}$ shows up, it is perhaps too much to expect that the description will clearly determine whether $\mathrm{P}$ is or is not relevant for classification under $\mathrm{M}$ and if it is, whether the sample or exemplar must be, or not be P.

It is even more striking that anti-descriptivists following the Kripke-Putnam approach would feel such allegiance. The Kripke-Putnam model postulates that the classification of things or samples into kinds depends on the similarities to original paradigms. Since things are similar and dissimilar in many respects, it seems that it is too much to expect that the similarity or similarities that are responsible for classification be fixed, for any term, once and for all, at the very moment of introduction. 
Wilson's 'ave' case is fictional. But there are a good number of real life cases that have come to cast doubt on the once-and-for-all stance. David Plunkett and Timothy Sundell (2014) have recently discussed a case, brought up by Peter Ludlow (2008) involving the predicate 'athlete'. In 1999 the horse Secretariat appeared on the ESPN list of the greatest athletes of the 20th century. ${ }^{3}$ The debate that ensued was about whether the meaning of the term allowed its application to non-humans. This is an interesting case because no matter which theory of meaning the debaters endorsed (descriptivism or anti-descriptivism), the debate hinged on whether the meaning of 'athlete' definitely excluded or included non-humans since its introduction as a meaningful term in the language. For if it excluded them, accepting the application of 'athlete' to Secretariat would constitute a (welcome or unwelcome) break with the previous usage of 'athlete'.

Now, the application of 'athlete' to non-humans has clearly not gained traction; the Secretariat case appears to be rather anecdotal and, as we are using the term nowadays, 'athlete' applies only to humans. Imagine though that, on the wake of the debate about Secretariat, it had become common to include horses in lists of athletes. It is not clear that such inclusion would constitute a change, neither slight nor radical, in the meaning of 'athlete'. After all the similarity being highlighted as relevant or important that would lead us to classify non-humans as athletes seems well within the umbrella of the similarities that we use to apply the term.

Contemplating such a possibility is indeed contrary to the presumption that the domain of application is fixed once and for all. Reflection on cases such as 'ave' and 'athlete' suggests that the semantics of some terms is flexible in that, at a given point in time, when the issue arises as to whether to classify an object or a sample or a phenomenon under the term's extension, there may be more than one open course of action compatible with the meaning of the term, more than one course of action continuous with previous usage. ${ }^{4}$

Flexibility should not be reduced to other phenomena. On the face of cases such as the 'athlete' case, it is common to encounter the response that the use of 'athlete' underlying the ESPN list was metaphorical. Of course, the response goes, had the practice become established, the metaphor would have died, the meaning of 'athlete' suffering a not too radical change (but change after all) adapting to the new usage.

We think, though, that the extremely lively discussion that erupted after the ESPN list included horses in their best-athletes list shows that the usage was not meant to be metaphorical. No such discussion would have erupted surrounding the metaphorical use of other expressions such as 'the pearls in his mouth'. The discussion was about whether Secretariat and other non-humans could be classified as bona fide athletes. No such discussion arises as to whether people's teeth are bona fide pearls. Moreover, as

\footnotetext{
${ }^{3}$ Secretariat was number 35 and there were two other non-humans in the ESPN list, both racing horses: Man o'War (number 84) and Citation (number 97).

${ }^{4}$ We could say that flexibility or inflexibility as regards the use of a term $t$ is an attribute of the community not of the semantics or the use of the term. But the phenomenon has immediate semantic consequences, for it translates into the semantic permissibility of alternative paths as regards what is included and what is excluded from the extension of $t$.
} 
we mentioned before, in the intended application of 'athlete' to Secretariat and other horses, the similarity being highlighted as relevant or important, a similarity that would lead us to classify non-humans as athletes, seems well within the umbrella of the similarities that we use to apply the term. The 'ave' case cements also the argument: it is clear that in the decision to apply, or not to apply, 'ave' to planes, there is no metaphorical intent on the part of the Druids.

Semantic flexibility has been acknowledged in different ways and with different consequences by different authors. For instance, Joseph LaPorte has argued, against Putnam, that "vernacular terms for substances like water or minerals are vague in such a way that it is not clear whether a new substance with the familiar superficial features but a different microstructure, or a new substance with unfamiliar superficial features but the same microstructure, would belong in the extension of a term" (LaPorte 2004: 103). According to LaPorte pre-scientific uses of terms are open-textured, and as science progresses, it is not determined in all cases whether a term should apply to a given sample or exemplar: "Empirical exploration uncovers many plausible candidates" (LaPorte 2004: 3). Thus experts do have a choice, and their choice refines a term's meaning.

LaPorte endorses the view that some terms have what we have called here a flexible semantics, proposing that meaning evolves without there being a clean break in usage. In that sense he clearly rejects the once and for all interpretation of the tenet that meaning determines extension.

Flexibility is also acknowledged by Henry Jackman. Jackman (1999) has argued that at any given point in the history of the use of a term there are alternative possibilities of extension of the domain of application, alternative equilibria, that are consistent with past practice: “A practice can evolve as its characterization of a term's meaning is made more determinate, but it need not actually be viewed as changing unless it settles on an equilibrium that was not a member of the set originally accessible to it. As long as the practice remains the same, so does the meaning of the term tied to it" (Jackman 1999: 160-1). Jackman, unlike LaPorte, does not see the alternative possible histories of the use of a term as refinements of precisifications of the meaning, but just as preservations of meaning.

Different terms or different kinds of terms may have more or less accessible equilibria. Some terms may have very few, or perhaps no alternative equilibria, and for those terms the domain of application is indeed fixed once and for all: when the term is bestowed a meaning, there is only one possible history of correct application.

Jackman's view challenges the traditional view that would admit only one possible history of application compatible with a pre-established meaning in a further, more radical way. For on Jackman's view we have to accept that future developments affect present and past practice. Jackman proposes a form of "temporal externalism" according to which "the future behaviour of an individual or his society can affect the content of his thoughts and utterances" (Jackman 199:160), a view that he sees in full consonance with the kind of externalism endorsed by Kripke, Putnam and Tyler Burge. On Jackman's view, past applications of a flexible term (i.e., a term, for which there is more than one accessible equilibrium) $t$ to $a$ are de facto wrong if the subsequent history of the use of the term does not include $a$ under the extension of $t$. It is not just that we, 
present speakers, judge them as wrong: they are wrong because correctness of application, as well as the content of utterances and thoughts, is relative to the alternative histories of the use of the term.

Jackman's stance on the role of future facts on past performance is a bold step not intrinsically connected to the view that the semantics of some terms is flexible. One may be more inclined to take a position closer to LaPorte's and accept that there is a certain level of indeterminacy as regards whether the application of $t$ to $a$ is consistent with the meaning of $t$, an indeterminacy that future practice resolves. Even if we deny it factual import, something like Jackman's picture is useful to explain some of our attitudes towards past ways of applying terms and our tendency to judge as wrong an application of $t$ to $a$ by our ancestors, on the basis of future development or refinement in the application of a term. Even though the usage of some terms may well be flexible, once a possible history of usage gets consolidated, that form of usage becomes expansive towards the past: we tend to look at the past as if that form of application of the term had always been the only possibly correct one.

Flexibility is time sensitive. We can see LaPorte's history of how the meaning of a term is refined in its path from the vernacular domain to the scientific domain as a process of inflexibilization. Flexibility is also a matter of degree. Some terms may be extremely flexible in that several different equilibria are compatible with continuous use. Other terms may simply be inflexible: only one linear history is compatible with the meaning of the term. Some scientific terms seem to be inflexible. For instance Nigel SabbartonLeary (2010) has argued that the meaning of 'tungsten' is given by the description 'the element with atomic number 74'; past, present and future uses of 'tungsten' correctly apply only to that substance. For semantically inflexible terms, the traditional strong and once-and-for-all interpretation of the principle that meaning determines reference does hold.

It may seem that our argument supports the conclusion that all terms are flexible. Not so. It is important to distinguish here two issues. On the one hand any kind term could have been associated with a different extension. The sound 'table' could have been applied to tables and chairs, but that does not make the term flexible. The issue of flexibility comes up when there is a consistent and continuous practice of application of a term to a certain domain, and then the question arises as to whether the term is to be applied to an object or sample that is in some ways similar to, and in some other ways dissimilar from, members in the extension. In the case of 'ave' planes are similar to the objects the term had been always applied to, in that they fly; but they are dissimilar also since they are not living organisms. If the semantics of the term is flexible, the options of including or excluding the new objects from the extension are equally consistent with past usage. For an inflexible term, like 'tungsten', the criteria are strict and no question arises. Whether the semantics of a term is flexible or inflexible depends on many factors, including the intentions and interests of the speakers, and what is at stake in keeping the extension fixed. Inflexibility is important for science. It helps explain why it makes sense to regard as wrong past applications of scientific terms in spite of radical changes in the theory.

Admitting semantic flexibility invites the question as to what makes the history of the use of a flexible term go one way or another. LaPorte, focusing on pre-scientific uses of terms, suggests that it is the task of experts to push usage in a certain direction. But as 
we will argue, a variety of factors do have an influence. Money, politics, social pressure, ethical considerations, the intelligence of a few actors with a capacity to move others to use words in one or another way, all may play a role in a phenomenon that is quite pervasive, as there are many terms with an arguably flexible semantics.

Think, for instance, of e-sports. Video game competitions are nowadays a social phenomenon that brings together millions of players, and have become a business of great proportions. The interest those competitions raise has resulted in the participation of sponsors and the creation of an international federation. And there is an ongoing discussion as regards the recognition of e-sports qua Olympic sports for the Tokyo Games of 2020. In fact, since the end of 2017 the IOC has already recognized that they could be considered a sporting activity, highlighting features such as the intensity of the training which is comparable with traditional sports. ${ }^{5}$

But of course, the decision by the IOC might go the other way. Decisions as regards application or non-application of terms to things often depend on which similar features end up being highlighted as relevant. And which features end up being highlighted as relevant is not a purely semantic issue. In this case, like in many others, there is little doubt that commercial impact, generational differences and changing social attitudes may, and probably do, play a role.

This case highlights also that cashing out the addition of e-sports to the extension of 'sport' as an evolution or refinement of the meaning of 'sport' as opposed to simply counting it (as Jackman would have it) as an alternative choice that entirely preserves the meaning of the term, is not an easy choice. Does classifying e-sports as sports constitute a precisification or refinement in the meaning of 'sport'? It is tempting to say that it does, after all if we accept that the decision could go the opposite way we are implicitly accepting that before the decision it is indeterminate whether e-sports are or are not sports. In fact, a very common reaction among philosophers and nonphilosophers alike, is to express surprise that an activity such as playing video games can be considered a sport, and consequently the classification of the activity as a sport is viewed as stretching the meaning of 'sport'. Stereotypes play a role in our judgments about meaning too. And the stereotype of the typical video game player, a kid permanently dressed in pyjamas, locked in their room all day and consuming cold pizza and Coca-Cola, does not invite an immediate connection to the (stereotypical) world of sports. But the stereotypes of darts and snooker, typical pub activities, do not invite such a connection either. Yet, snooker has been considered a sport for a long time and in fact it was a sport in the Paralympic Games from 1960 till 1988. And there are voices that claim the same destiny for darts. ${ }^{6}$ It is worth noting that in both cases, the emergence of sponsors, surely not a semantic matter, appears to have an influence in the classification. In any case, if darts and snooker are sports it is not entirely clear what stretch in the meaning of 'sport' including video games consists in. ${ }^{7}$

\footnotetext{
${ }^{5}$ See https://www.olympic.org/news/communique-of-the-olympic-summit, Jenny et al. (2017) and Pérez Triviño (2017).

${ }^{6}$ See http://www.rulesofsport.com/faq/is-pool-snooker-a-sport-or-a-game.html and http://www.rulesofsport.com/faq/is-darts-a-sport.html

${ }^{7}$ Unless of course one wishes to argue that any addition of a newly encountered or created thing or kind of thing, or any subtraction or a previously included item is a change in meaning. We do not think that such a strategy is well founded. As John Perry
} 
A case that clearly highlights the interplay between semantic flexibility and inflexibility involves the dispute over same-sex marriage, a dispute that has occurred both in the street and in the law. Among supporters of same-sex marriage, the discussion has moved along two different lines. On the one hand we find those that, accepting that traditional marriage involves the union of woman and man, declare the traditional institution of marriage defunct and see the acceptance of same-sex marriage as the dawn of a new institution for which we may want to continue to use an old word with a new meaning. Thus, Brian Epstein (2015) states:

At its core - in belief, in practice, in function and in law - the old institution of marriage applied exclusively to opposite-sex couples. Which is why the old institution is now being replaced with a better one [. . .] [T] he word "marriage" is now undergoing a reference change [...] we are making a social decision to apply an old word to a new institution.

On the other hand Adèle Mercier, who acted as expert witness in Canadian Courts, defending gay couples seeking the right to marry, considers in Mercier (2007) a semantic argument according to which the characteristic features that define a marriage (commitment to a life in common, respect, trust, etc.) are present in heterosexual as well as same-sex unions, in which case same-sex marriage would have always been under the extension of 'marriage'. 8

Both argumentative lines subscribe to what we have termed here the inflexible stance: according to the first line of thought, it was determined by past uses of 'marriage' that same-sex unions did not fall under the umbrella of 'marriage', and hence a very welcome change in the meaning of the word occurred when same-sex marriage was legalized. According to the second line of thought same-sex unions had always been under the extension of marriage.

Another way of looking at the issue is to consider 'marriage' as a term with a flexible semantics, in which case, adapting Jackman's terminology, at the time same-sex unions came up for classification two relevant and different equilibria were consistent with the meaning of the term, one of them accepting the application of 'marriage' to same sex unions, and the other one restricting it to unions of woman and man. Social pressure and, in many countries, the decisions of judges, have moved towards the inclusion of same sex unions as marriages. ${ }^{9}$ Here too, the difference between an approach that cashes out the decision between alternative courses of action as a matter of precisification or refinement of meaning and an approach that is closer to Jackman's temporal externalism is important in the assessment of past judgments about same sex marriage. For, given the actual history of the use of the term, a temporal externalist like Jackman would regard past uses by judges and other officials that denied the application of the term to same-sex unions as wrong, as always the facto wrong, for the reference of

(2011) has argued, the addition of the red-eared frog to the list of endangered species does not alter the meaning of 'endangered species'.

${ }^{8}$ This line of argument is not the one ultimately recommended by Mercier to be the basis for the judges' decision. See Mercier (2007).

${ }^{9}$ An interesting issue has to do with whether judges can establish meaning. See Epstein (2015) for an argument against judges' semantic authority. 
their utterances, and the thoughts they expressed using the word 'marriage' were shaped by the future history of the use of the term. Had the history of the word been different, they would have been correct. Accepting, on the other hand, that flexibility entails a certain degree of indeterminacy, the response is rather that prior to the decision to settle on a given alternative consistent with past usage, there was no right or wrong as regards the meaning and the application of the term (which does not entail, obviously, that there was no right nor wrong judging the case from an ethical or social point of view).

It is not our purpose here to discuss which of the ways of interpreting this and other situations is the correct one. ${ }^{10}$ As stated before, our main objective is to clarify a distinction in the mode of semantic operation of kind terms and to clarify also the commitments that the different positions espouse as regard the correctness or incorrectness of judgments about the application of terms to particular cases.

\section{Section 2. Tolerance}

Another relevant semantic distinction that is different from and orthogonal to the flexibility vs inflexibility contrast has to do with the acceptability of the co-existence of different uses of a given term that divide roughly the same domain of application in different ways. In cases in which two (or more) acceptable uses cohabitate, the different uses correspond intuitively to different meanings. But, as we will see, there are cases in which the cohabitation of different uses is not legitimized by the speakers' community and is not even permissible from a semantic point of view. When different uses that are meant to apply to roughly the same domain, but that divide it in different ways, coexist in a community, we can say that the usage is tolerant. ${ }^{11}$ When coexistence of different practices of use is not tolerated we can say that the semantics of the term is strict.

It is clear that the distinction between tolerant and strict usage differs from the distinction between flexible and inflexible semantics. The semantics of a use of a term $t$ may be inflexible, in that it does not contemplate as continuous with the same meaning any expansion or contraction of the domain of application; and yet, other uses (flexible or inflexible) that do not apply $t$ to a class of objects in the original inflexible extension of $t$, or vice versa, may be legitimized by the community and permitted by the otherwise inflexible semantics of (a usage of) $t$. A few everyday life examples will help bring the point home.

Late in the 19th century merchants sought to recover taxes paid on tomatoes, arguing that tomatoes should be exempt of duty like all the other fruits. The case was heard by the US Supreme Court that in 1893 found in favor of the tax collectors and against the merchants (149 US 304, 1893). At the time everybody agreed, as we all agree nowadays, that tomatoes are botanically classified as fruits. But there was, and there is, a consolidated culinary use of words excluding tomatoes from the category of fruits. Justice Gray (cited by Phillips 2014: 381) wrote the opinion:

${ }^{10}$ Although the authors do have, of course, their own sympathies, not entirely consonant with one another.

${ }^{11}$ Again, as in the case of flexibility, it could be said that it is the community that is or is not tolerant in its usage. And, like in the case of flexibility the semantic impact of the attribution of tolerance or strictness should be clear, for the level of tolerance depends crucially, as we will see, on the intentions that bestow meaning on a term. 
Botanically speaking, tomatoes are the fruit of a vine just as cucumbers, squashes, beans and peas. But in the common language of the people, whether sellers or consumers of provisions, all these are vegetables which are grown in kitchen gardens, and which whether eaten cooked or raw, are, like potatoes, carrots, parsnips, turnips, beets, cauliflower, cabbage, celery and lettuce, usually served at dinner in, with or after the soup, fish or meats which constitute the principal part of the repast, and not, like fruits generally, as dessert.

The ruling does not strike us as mistaken even though, as we all learn in school, tomatoes are, botanically speaking, fruits. For it appeals to a use of the word 'fruit' common in 1893 and still well established today, even among botanists. ${ }^{12}$

The intentions of speakers in introducing and using a term such as 'fruit' does not disallow the co-existence of the two practices of use, the two ways of using, or meanings of the word 'fruit' that cut the domain of application in different ways, as the culinary use excludes tomatoes from the extension of 'fruit' and the botanical use includes it. ${ }^{13}$ Our usage of 'fruit' is tolerant. Our acceptance of the culinary use shows that our application of terms for kinds of things is not always guided exclusively by the intention to capture the nature of kinds, and that we are not always committed to fall in line with scientific or expert uses. The use of 'fruit' is not underwritten exclusively by the fundamental intention by speakers to refer to a natural, botanical, category.

Now, clearly the tolerance as regards the different uses of 'fruit' is independent of the inflexibility or flexibility of each of the uses. If Kripke and Putnam are right and scientific terms aim to capture the underlying essence of kinds, the botanical use of 'fruit' is inflexible. Needless to say, the status of biological and botanical terms is hotly debated, and the Kripke-Putnam approach has been characterized as naive and inaccurate. But this is beside the point: even if the allegedly simplistic approach to biological kinds that Kripke and Putnam endorse were correct, and even if there is an underlying essence that all fruits share, an essence targeted by the botanical use of 'fruit' (rendering the botanical use of 'fruit' inflexible), nothing follows from that inflexibility as regards the acceptability of the existence of a culinary use of the term 'fruit'. ${ }^{14}$

${ }^{12}$ An interesting question has to do with what makes one or the other use of 'fruit' correct in different contexts. That, we contend depends on all kinds of non-semantic factors, having to do with the broad context of use. But the issue is rather complex as it affects also the correctness of a judicial ruling. In the 1893 case it seems quite clear that the focus on the culinary use was sound. Had the dispute been about scientific issues, the appeal to the culinary use of 'fruit' might have been incorrect. We are not espousing here a robust conception of legal correctness, in the sense of Dworkin's (1977) right answer thesis. We keep neutral between that approach and an approach closer to Kelsen's (2005, chapter 8), a view that appeals only to the culturally acceptable character of interpretations in legal contexts.

${ }^{13}$ Some may argue that the phenomenon highlighted here is pragmatic, explained in terms of modulation or enrichment. Here we are taking a classical stance, and we regard the differences between different usages as semantic.

${ }^{14}$ Tolerance, like flexibility, is a time sensitive phenomenon. More than one use may be acceptable at a given point and not at another. It is interesting to note also that the 
In contrast, the way some terms are used in a language simply precludes the acceptability of the coexistence of different uses and imposes a strict semantic mode of operation. In the past, patients in temporary cardiac arrest or people with severe cases of catalepsy that would have revived spontaneously were often pronounced dead. Many of them were buried or cremated. It was wrong to declare them dead, and those who made the pronouncement were making a mistake. ${ }^{15}$ Their application of the term was surely guided by the conception of death that was common currency at the time. But 'dead' meant, then and now, dead.

As Michael Moore has pointed out:

Both we and they [our ancestors] intended to refer to the thing, the naturally occurring kind of event, that death is. If they knew what we know about revivability of persons [ . . ], they would also say that such persons are not dead. They would say this because they, like we, intended to refer to a thing whose nature is partially known; and they, like we, would change the conventional indicators of when someone is dead whenever a better scientific theory comes along that demands that we do so. (Moore 1985: 297-298)

The fundamental intention by speakers using 'dead' and 'death' has always been to refer to the real phenomenon of death, the irreversible cessation of vital functions, as indicated in the Uniform Determination of Death Act, even if conceptions of death and what being dead consists in have changed throughout history and have varied from community to community. It is crucial here to distinguish, as John Perry (2011) insists, the meaning of 'dead' and 'death' from the conception of death, the set of beliefs about the phenomenon that are commonly held at a given time. The meaning can be the same throughout time, even when conceptions change. This is what makes possible for people to disagree in their beliefs and yet be talking about and referring to the same thing.

Undeniably, the intention to refer to the natural phenomenon, a phenomenon that we keep learning about, is guided by interest: we do not want to be pronounced dead unless we are really dead. And it is that fundamental intention that accounts for the stability of meaning throughout new discoveries and changes of stereotypes and beliefs about the phenomenon. The meaning or use of 'dead' and 'death' is strict, in that no other legitimate or acceptable usage or meaning, a use that cuts the same domain of application, organisms, in a different way is deemed acceptable. That acceptability is not a contingent societal matter: it is embedded in the semantics of the term, for it is constitutive of the intentions that govern the introduction and transmission of the use of terms, intentions that establish meaning. Whether usage is tolerant or strict depends on whether the intentions of the speakers in introducing a term and bestowing it a meaning exclude other uses.

cohabitation of uses is not always peaceful, and often one use ends up prevailing while another one is abandoned. An illustration of this point is the case of the culinary use of 'fish', a usage that included cetaceans in the past and that definitely excludes them in the present.

${ }^{15}$ This is not to say that they were legally at fault. They simply lacked the knowledge we possess now. 
An important clarification is in order: first, it may seem that Moore's point depends on a counterfactual claim as to what our ancestors would have done were they to know what we know nowadays, and it is tempting to point out that there is no way to tell what people would or would not do as regards the continued application of a term. But in fact, Moore's point does not depend on a counterfactual. We know well what our ancestors actually did: they did "change the conventional indicators of when someone is dead" when "a better scientific theory" came along. But more importantly, the objection that our ancestors might have decided to use 'dead' even for those cases in which people were found to revive, perhaps accepting sentences such as 'some dead people revive, but some stay dead' misses an important point: that had our ancestors decided to use 'dead' for revivable cataleptic people or for people in cardiac arrest, we still would want to target the natural irreversible phenomenon that we intended to target when introducing 'dead' and 'death', that phenomenon whose occurrence justifies burying or cremating the dead. Had we not had a word for it, we would probably have invented it. ${ }^{16}$

Consider also the expression 'human being'. Whole communities in the past did not consider members of other races human beings. But independently of the conception people had of human beings, all human beings are and have always been under the extension of 'human being'. Our use of the expression is strict, and no other use that leaves part of its extension out is tolerated by its very semantics. ${ }^{17}$

Both 'dead' and 'human being' are high stakes expressions; their correct application is a matter of great importance, and this may be why accepting the coexistence of uses that include other things in the extension or that exclude portions of it is not tolerated, as those other uses may be frivolous, dangerous or damaging. The semantics of 'dead' and 'human being' is not tolerant.

It may be tempting to think that tolerance goes hand in hand with flexibility (and strictness with inflexibility). For instance 'dead', an expression used strictly, is, we surmise, clearly inflexible: at any point in time, using 'dead' to include people in reversible states is not a possible alternative continuous with the meaning of 'dead'.

But the two pairs of distinctions do not go hand in hand. As we have seen, the tolerant usage of 'tomato' does not exclude, in and of itself, regarding one of its uses, the botanical one, as inflexible (even if, as we noted, it is controversial how inflexible some scientific uses are) while regarding the other use, the culinary one, as flexible. In the culinary usage, whether items such as tomatoes or avocados are classified as fruits or vegetables may depend simply on the cuisine fashion set up by trendy chefs.

As regards flexibility, the case of 'human being' is particularly complex. In the light of recent advances in the creation of artificial life, some may argue that we will soon be presented with a choice in the classification of certain beings as human, which would

${ }^{16}$ Surely there are other uses of 'dead' ('dead battery'; 'dead marriage'; 'dead color' . .). We are interested here in the core meaning from which all those other uses have sprung metaphorically. The latter are, excuse the pun, dead metaphors.

${ }^{17}$ Could a group of people succeed in introducing an expression that separated some human beings from other human beings, and proceed to use it to discriminate against some groups? Unfortunately, yes, of course, they could. But (as we have argued in the case of 'death'), it would not be our expression 'human being'. 
seem to suggest that there is a certain level of flexibility in the semantics of 'human'. Others may argue that the term is inflexible: using 'human being' in the past to exclude members of some races was not a possible alternative continuous with the meaning of 'human being'; and as regards the future, right or wrong decisions may be made concerning the expression's application, but there is an essence to humanity and hence it is determined whether a being is or is not human. The discussion of this issue and its ethical implications is well beyond the scope of this paper, but in either case, we think, the semantics of the expression is not tolerant: the cohabitation of uses that disagree in their inclusion or exclusion of certain groups of beings will not, and should not, be acceptable.

Finally, although this is also controversial, we have seen that it is possible to regard the meaning of 'marriage' as flexible. And, at the same time it is clear that different uses, one that categorizes a union as marriage and another one that categorizes it as not marriage cannot officially coexist in a community.

There may be disagreements as regards whether the terms we use here as illustrations are really instances of semantic flexibility, inflexibility, tolerance or strictness. This does not detract from the fact that the two pairs of distinctions are conceptually different and account for different explanations of the adequacy or inadequacy of the application of kind terms.

\section{Conclusions}

In this paper we have discussed two orthogonal distinctions that concern the use and the mode of application of kind terms. On the one hand, we have argued, some terms are used flexibly, in that the domain of application of the term can expand or contract. The use of other terms is inflexible: the extension is fixed once and for all, and any change in the domain of application is an error or a clean break with past practice, with the subsequent emergence of a new usage. Whether a term is used flexibly or inflexibly depends on all kinds of factors and accidents surrounding the history of its use.

On the other hand we have explored cases in which the cohabitation of two different uses of a kind term that divide roughly the same domain of application in different ways is tolerated, and we have distinguished those from cases in which only one use is accepted.

The two pairs of distinctions account in different ways for the judgments of correctness or incorrectness of applications of terms, and thus they contribute to explain the source and import of some disagreements, both in everyday life and in the legal sphere. ${ }^{18}$ The dispute around whether tomatoes should be exempt of duty had to do with the acceptance of more than one use of the term 'fruit', not with whether alternative paths of use that expanded or contracted the domain of application were compatible with established usage. It is the question of tolerance that plays a role in the explanation of that dispute. On the other hand, the controversy around e-sports and the inclusion of

${ }^{18}$ It is worth stressing also that the distinctions are entirely independent of whether the theory of meaning endorsed is descriptivist or anti-descriptivist. For a discussion of how different theories of meaning account for legal disagreements see Martí and RamírezLudeña (2016) 
video gaming under the umbrella of the term 'sport' is not a question about the acceptance of the cohabitation of different uses of the word 'sport' in the community. It has all to do with whether the inclusion of video games is consistent with the prior use of the term. Distinguishing the distinctions is important in order to provide adequate explanations of the sources of disagreements. ${ }^{19}$

\section{$\underline{\text { References }}$}

Dworkin, Ronald (1977): 'No Right Answer?'. PMS Hacker and J. Raz (eds.): Law, Morality and Society: Essays in Honour of HLA Hart. Oxford, Clarendon Press: 58-84.

Epstein, Brian (2015): https://opinionator.blogs.nytimes.com/2015/02/16/whatalabamas-roy-moore-gets-right/

Jackman, Henry (1999): 'We Live Forwards but Understand Backwards: Linguistic Practices and Future Behavior’. Pacific Philosophical Quarterly, 80: 157-177.

Jenny, S.E., Manning, R.D., Keiper, M.C. and Olrich, T.W. ( 2017): 'Virtual(ly) Athletes: Where eSports Fit Within the Definition of "Sport"'. Quest 69 (1): 1-18, DOI: $\underline{10.1080 / 00336297.2016 .1144517}$

Kelsen, Hans (2005): Pure Theory of Law. Clark, New Jersey, The Lawbook Exchange Ltd.

LaPorte, Joseph (2004): Natural Kinds and Conceptual Change. Cambridge University Press.

Ludlow, Peter (2008): 'Cheap Contextualism'. Philosophical Issues, 18: 104-129.

Martí, Genoveva and Ramírez-Ludeña, Lorena (2016): 'Legal Disagreements and Theories of Reference'. A. Capone and F. Poggi (eds): Pragmatics and Law.

Philosophical Perspectives. New York. Springer, 2016: 121-139.

Mercier, Adèle (2007): 'Meaning and Necessity: Can Semantics Stop Same-Sex Marriage?'. Essays in Philosophy, 8(1). Article 14.

Moore, Michael (1985): 'A Natural Law Theory of Interpretation'. Southern California Law Review, 58: 277-398.

\footnotetext{
${ }^{19} \mathrm{We}$ are very grateful to two anonymous referees for Synthese for their helpful comments and suggestions. We are also grateful to Carl Hoefer, Diego M. Papayannis, José Luís Pérez Triviño and Josep M. Vilajosana for comments and discussion. Versions of this paper were presented at the Conference Natural Kinds: Ontology and Semantics (Universidad Complutense de Madrid, March 2017), the Metaphysics in the Law Conference (Universitat de Barcelona, May 2017) and the Seminar in Metaphysics (Universitat de Barcelona, March 2018), and we are grateful to the audiences. We have also benefited from discussion with The Zoom Group. We acknowledge the support of the Spanish MINECO (DER2016-80471-C2-1R and FFI2015-70707-P), the AGAUR of the Generalitat de Catalunya, and the Diaphora Project (H2020-MSCA-ITN-2015675415).
} 
Pérez Triviño, J.L. (2017): 'Los retos jurídicos de los e-Sports'. Revista Jurídica LaLiga, 6: 1-8.

Perry, John (2011): 'Textualism and the Discovery of Rights'. Andrei Marmor and Scott Soames (eds.): Philosophical Foundations of Language in the Law. Oxford, Oxford University Press: 105-129.

Phillips, Ian (2014): 'Cetacean Semantics'. Analysis, 74 (3): 379-382.

Plunkett, David and Sundell, Timothy (2014): 'Antipositivist Arguments from Legal thought and Talk. The Metalinguistic Response'. G. Hubb and D. Lind (eds.):

Pragmatism, Law, and Language. London, Routledge: 56-75.

Putnam, Hilary (1975): 'The Meaning of 'Meaning'. K. Gunderson (ed.): Language, Mind and Knowledge. Minnesota Studies in the Philosophy of Science, VII. University of Minnesota Press: 131-193.

Sabbarton-Leary, Nigel (2010): 'Descriptivist Reference from Metaphysical Essence'. dialectica 64(3): 419-433.

Wilson, Mark (1982): 'Predicate Meets Property'. The Philosophical Review, 91 (4): 549-589. 